doi: $10.1017 /$ S204017441400022

\title{
Arsenic exposure in early pregnancy alters genome-wide DNA methylation in cord blood, particularly in boys
}

\author{
K. Broberg ${ }^{1,2 *}$, S. Ahmed ${ }^{1,3}$, K. Engström ${ }^{2}$, M. B. Hossain ${ }^{1,2}$, S. Jurkovic Mlakar ${ }^{4}$, M. Bottai ${ }^{5}$, M. Grandér ${ }^{1}$, \\ R. Raqib ${ }^{3}$ and M. Vahter ${ }^{1}$ \\ ${ }^{1}$ Institute of Environmental Medicine, Unit of Metals and Health, Karolinska Institutet, Stockholm, Sweden \\ ${ }^{2}$ Department of Laboratory Medicine, Section of Occupational and Environmental Medicine, Lund University, Lund, Sweden \\ ${ }^{3}$ International Centre for Diarrhoeal Disease Research Bangladesh (ICDDR,B), Dhaka, Bangladesh \\ ${ }^{4}$ Department of Clinical Biochemistry, Faculty of Pharmacy, University of Ljubljana, Ljubljana, Slovenia \\ ${ }^{5}$ Unit of Biostatistics, Institute of Environmental Medicine, Karolinska Institutet, Stockholm, Sweden
}

\begin{abstract}
Early-life inorganic arsenic exposure influences not only child health and development but also health in later life. The adverse effects of arsenic may be mediated by epigenetic mechanisms, as there are indications that arsenic causes altered DNA methylation of cancer-related genes. The objective was to assess effects of arsenic on genome-wide DNA methylation in newborns. We studied 127 mothers and cord blood of their infants. Arsenic exposure in early and late pregnancy was assessed by concentrations of arsenic metabolites in maternal urine, measured by high performance liquid chromatography-inductively coupled plasma mass spectrometry. Genome-wide 5-methylcytosine methylation in mononuclear cells from cord blood was analyzed by Infinium HumanMethylation450K BeadChip. Urinary arsenic in early gestation was associated with cord blood DNA methylation (Kolmogorov-Smirnov test, $P$-value $<10^{-15}$ ), with more pronounced effects in boys than in girls. In boys, $372(74 \%)$ of the 500 top CpG sites showed lower methylation with increasing arsenic exposure $\left(r_{S}\right.$-values $\left.>-0.62\right)$, but in girls only 207 (41\%) showed inverse correlation $\left(r_{S}\right.$-values $\left.>-0.54\right)$. Three CpG sites in boys (cg15255455, cg13659051 and cg17646418), but none in girls, were significantly correlated with arsenic after adjustment for multiple comparisons. The associations between arsenic and DNA methylation were robust in multivariable-adjusted linear regression models. Much weaker associations were observed with arsenic exposure in late compared with early gestation. Pathway analysis showed overrepresentation of affected cancer-related genes in boys, but not in girls. In conclusion, early prenatal arsenic exposure appears to decrease DNA methylation in boys. Associations between early exposure and DNA methylation might reflect interference with de novo DNA methylation.
\end{abstract}

Received 4 December 2013; Revised 3 March 2014; Accepted 17 March 2014; First published online 14 April 2014

Key words: $450 \mathrm{~K}$, cancer, CpG, development, epigenetic, fetal

\section{Introduction}

The environment of the developing child is an important determinant of disease susceptibility in later life. ${ }^{1}$ This phenomenon may be mediated through epigenetic changes, such as alterations of DNA methylation, which alter developmental programming. ${ }^{2-5}$ Lately, it has become increasingly clear that toxic chemicals can also affect DNA methylation..$^{6-8}$

Arsenic, which frequently occurs at elevated concentrations in drinking water worldwide, is a potent carcinogen, a general toxicant and an endocrine disrupter. ${ }^{9,10}$ Besides the accumulating evidence for associations between in utero arsenic exposure and impaired fetal and child health and development, ${ }^{11-14}$ both human and experimental animal studies indicate higher risk for cancer, cardiovascular effects and increased mortality later in childhood or adulthood when exposure starts prenatally or shortly after birth. ${ }^{15-20}$ These results suggest persistent longterm effects of early-life changes, possibly through alterations of

*Address for correspondence: K. Broberg, Institute of Environmental Medicine, Unit of Metals and Health, Karolinska Institutet, 17177 Stockholm, Sweden.

(Email karin.broberg@ki.se)
DNA methylation at the 5-methylcytosine position. Studies on epigenetic effects of arsenic mainly have concerned changes in DNA methylation in relation to cancer development, which is closely related to DNA methylation instability. ${ }^{21-25} \mathrm{In}$ particular, arsenic-related changes in gene methylation status have been proposed to silence tumor-suppressor genes, possibly eading to long-term changes in the activity of genes controlling cell transformation. ${ }^{21}$ These results suggest that arsenic has epigenetic effects related to its carcinogenicity. Genome-wide DNA methylation has been assessed in a small group $(n=16)$ of adults. ${ }^{26}$ Studies on the effects of arsenic exposure on DNA methylation in newborns are few and have generally examined non-gene-related markers of DNA methylation. ${ }^{27-29}$ A recent study by Koestler et al. ${ }^{30}$ investigated the association between low maternal arsenic exposure measured in late pregnancy and genome-wide effects on 5-methylcytosine methylation in cord blood. Therefore, the aim of the present study was to evaluate cord blood DNA methylation of gene-related $\mathrm{CpG}$ sites, covering a large part of the whole epigenome, in relation to a large range of maternal arsenic exposure in both early and late pregnancy. Considering the increasing evidence for sexual dimorphism both for programming trajectories and in response 
to the environmental insults, ${ }^{31}$ including arsenic, ${ }^{29,32}$ we evaluated the results in female and male newborns separately.

\section{Methods}

\section{Study area and design}

The study area, Matlab, is a rural area southeast of Dhaka, where the International Centre for Diarrhoeal Disease Research, Bangladesh (ICDDR,B), runs a health and demographic surveillance system. In a population-based screening in 2002-2003, we found a total range of $<1$ to $3640 \mu \mathrm{g} / \mathrm{l}$, with $70 \%$ of the tube wells in Matlab exceeding the WHOrecommended limit of arsenic in drinking water of $10 \mu \mathrm{g} / \mathrm{l}^{33} \mathrm{In}$ an effort to decrease adverse health effect because of polluted drinking water, most families (>95\%) have had a well drilled in their yard past few decades ago, or obtain water from community-owned wells. $^{34}$ Unfortunately, a considerable fraction of those wells were later found to contain arsenic, because of the hydrogeological conditions, and this has been related to impaired fetal growth and increased infant morbidity and mortality. Other toxic exposures are low. This is a very pristine rural area of Bangladesh, with very little environmental pollution, for example, essentially no cars.

The study was nested in a large randomized populationbased food and micronutrient supplementation trial (MINIMat) in pregnancy. ${ }^{35}$ Pregnancy was identified by urine test, usually in gestational week (GW) 8. Women who tested positive were advised to visit the health facility for confirmation of pregnancy by ultrasound. The current study is based on 127 women who delivered at any of the health centers before early afternoon (5:00 am-2:30 pm, owing to logistics in transferring samples to the laboratory) from May 2003 to June 2004. According to the questionnaire, all women were nonsmokers, while $73(58 \%)$ of the women chewed betel leaves (6 out of 73 women reported betel chewing with tobacco) during pregnancy.

Birth weight was measured mostly within $24 \mathrm{~h}$ of delivery (all within $72 \mathrm{~h}$ ), using electronic scales. Socioeconomic status was based on family assets using data from the health demographic surveillance system database. ${ }^{36}$ Participants gave written informed consent and the study was approved by the Research Review Committee and Ethical Review Committee of ICDDR,B and the Regional Ethics Committee at the Karolinska Institutet, Sweden.

\section{Arsenic exposure}

Arsenic exposure was based on the sum concentration of arsenic metabolites [inorganic arsenic, methylarsonic acid (MMA) and dimethylarsinic acid] in spot urine samples collected, as previously described. ${ }^{37}$ This is an established biomarker that reflects exposure to inorganic arsenic from all sources. The halflife of arsenic in the body is $3-4$ days, which is why spot urine reflects the ongoing exposure. However, because the exposure in the area is mainly from drinking water, with some contribution from rice, the main staple food, the exposure is fairly stable over time. ${ }^{38}$ Because of the local custom that young women, especially first-time mothers, move to their parents' home for delivery, we evaluated arsenic exposure in both early and late pregnancy, using urine samples from 127 women that were collected between GW 5 and 14 (median GW 8) and between GW 26 and 36 (median GW 30), respectively. The relative amounts of the different metabolites in urine were used as markers of methylation efficiency. ${ }^{39}$ The reason is that we recently found that the efficiency of arsenic methylation increases very early in pregnancy. ${ }^{38}$ In particular, the percentage of MMA, which has been associated with increased risk of toxic effects in adults, ${ }^{40,41}$ decreased very early in pregnancy. The arsenic metabolite concentrations were measured using hydride generation atomic absorption spectrophotometry with a detection limit of $1.3 \pm 0.27 \mu \mathrm{g} / \mathrm{l}$. All arsenic concentrations were adjusted for variation in urine dilution by specific gravity to the average value, $1.012 \mathrm{~g} / \mathrm{ml}$.

\section{DNA isolation and epigenetic analysis}

Cord blood mononuclear cells were separated by Ficoll (Pharmacia-Upjohn) density gradient centrifugation. The epigenetic analysis has been described in detail elsewhere. ${ }^{42} \mathrm{In}$ brief, $1 \mu \mathrm{g}$ DNA $(50 \mathrm{ng} / \mu \mathrm{l})$ was bisulfite-treated (Zymo Research). The DNA samples were randomized for gender and arsenic exposure on two 96-well plates for analysis with the Infinium HumanMethylation450K BeadChip (llumina). All chips were from the same batch. We also included four controls in duplicate, with the duplicate positioned on different 96-well plates and different BeadChips. Three of the control samples were DNA extracted from blood and one was demethylated DNA (Zymo Research). The SCIBLU facility (Lund, Sweden) used $200 \mathrm{ng}$ bisulphite-treated DNA for hybridization to the BeadChip. Unsupervised hierarchial cluster analysis showed that all duplicates of the control samples clustered together.

For all samples, the number of detected CpGs ( $P$-value $=$ 0.01 ) were at least $>98 \%$. All 1500 probes (the top 500 selected for all children, top 500 selected for boys and top 500 selected for girls) performed very well with a detection $P$-value of at least 0.01 (the absolute majority $P<0.0001$ ) among $80 \%$ of the samples. In an ongoing study on DNA samples from whole blood we are evaluating the concordance between results from the HumanMethylation450K BeadChip and pyrosequencing. We found a correlation of 0.85-0.92 $(P>0.0001)$ for four different $\mathrm{CpG}$ sites tested for both methods.

Measurement of LINE1 methylation, as a marker for global methylation status, was performed on bisulphite-treated cord blood DNA from a subgroup of 80 newborns (median of maternal arsenic in urine at GW 8 was $66 \mu \mathrm{g} / \mathrm{l}$, range 3-740 $\mu \mathrm{g} / \mathrm{l}): 40$ boys and 40 girls. Measurement of four $\mathrm{CpG}$ sites in the LINE1 sequence was analyzed by the use of pyrosequencing, as described previously. ${ }^{43}$ 


\section{Statistical analysis}

Details of the statistical analyses were reported previously. ${ }^{7}$ Missing beta values $(0.1 \%)$ were imputed using $k$-nearest neighbor imputation $(k=10)$. Principal component analysis (PCA), using the R package swamp, was used to capture the major directions of variation in the data and influencing factors. For each of the top principal components, we fitted a univariate linear model with each of the sample annotations as regressors. The $\log 10 P$-values from the models' $F$-statistics were plotted as a heat map. The results showed that the analysis plate (two 96-well plates) was associated with methylation levels in the first $\left(P=10^{-6}\right)$ and third components $\left(P<10^{-10}\right)$. We removed the plate influence at each $\mathrm{CpG}$ site by using the residuals from the initial linear regression model of methylation with the analysis plate as regressor. The residuals of the linear model added to the total mean before correction became the new data for each $\mathrm{CpG}$ site. In this way, the methylation levels of the sites were not influenced by the analysis plate.

We first evaluated whether the maternal arsenic exposure (urinary arsenic) overall was associated with genome-wide DNA methylation by performing 482,421 separate linear regression models, one for each $\mathrm{CpG}$ site, with methylation as the dependent variable and arsenic concentration as the independent variable. The range of arsenic was rescaled to vary between 0 and 1 to minimize the potential effects of skewed data. We tested whether the slope was statistically significant in all 482,421 models. Had there been no effect of arsenic on any CpG site, then the slopes would result from mere sampling error. In this case, the $P$-values would be distributed uniformly over the $0-1$ range.

The associations of $\mathrm{CpG}$ site methylation fractions with urinary arsenic were then determined using Spearman correlation. Resulting $P$-values were corrected for multiple testing by the Benjamini-Hochberg method to obtain false discovery rates.

Some of the associations between DNA methylation and maternal urinary arsenic were non-linear, but after $\log 2$ transformation of the arsenic concentrations the associations showed linear patterns, and linear regression analyses were applied. We did not observe any typical genotype-related clustering of DNA methylation when visually inspecting the associations between arsenic and DNA methylation. In multivariable-adjusted analysis, we controlled for the maternal characteristics age, body mass index (BMI) (at GW 8), SES, as well as GW at urine collection, gestational age at delivery and fetal sex (except for analyses stratified for sex). In sensitivity analysis, we additionally adjusted for birth weight, betel chewing including with tobacco and cadmium.

For the pathway analysis, we used the Ingenuity Pathway Analysis Tool (Ingenuity H Systems). We selected the top 500 gene-annotated $\mathrm{CpG}$ sites associated with arsenic in maternal urine in boys and girls separately (from Illumina). Differentially methylated genes are mapped to genetic networks/diseases available in the Ingenuity Pathway Knowledge Base and then ranked by score.

\section{Results}

\section{Background data}

The studied women were on average 25.3 years old and with a BMI of $20.4 \mathrm{~kg} / \mathrm{m}^{2}$ (Table 1). The gestational age at birth was 39 weeks on average: 12 births (six boys and six girls) being premature (range 34.4-36.7 weeks at birth). Boys had slightly higher birth weight $(2838 \mathrm{~g})$ than girls $(2724 \mathrm{~g})$. The median maternal urinary arsenic concentrations were $66 \mu \mathrm{g} / \mathrm{l}$ in GW 8 and $89 \mu \mathrm{g} / \mathrm{l}$ in GW 30, with wide variations. Maternal urinary arsenic concentration did not differ by sex of the child. Women in the study sample were to a larger extent nulliparous, had higher SES and had children with somewhat higher birth weight, compared with the total cohort of 1729 pregnant women studied for arsenic exposure.

\section{Maternal arsenic exposure and genome-wide DNA methylation}

The PCA showed that maternal arsenic exposure in early gestation (GW 8) was associated with cord blood DNA methylation in the eighth component and, to a lesser extent, in the fourth component (Supplementary Figure S1). Arsenic exposure measured in late gestation (GW 30) showed weaker association with DNA methylation than that in GW 8.

We first evaluated whether maternal arsenic exposure in early gestation was associated with newborn genome-wide DNA methylation by analyzing all CpG sites in cord blood $v$. arsenic concentrations in maternal urine in GW $8(482,421$ separate models). Low $P$-values were more frequent than expected from a uniform distribution (Kolmogorov-Smirnov test, $P$-value $<10^{-15}$, Supplementary Figure S2), and there were marked differences between sexes; significant effects of arsenic were considerably more pronounced in boys compared with girls (Fig. 1). The proportion of small $P$-values was greater than expected in boys $(P$-value $<0.0001)$, but not in girls $(P$-value $=0.99)$.

We selected the top $500 \mathrm{CpG}$ loci with the lowest $P$-values based on their association with urinary arsenic levels in GW 8 and found hypomethylation with increasing arsenic exposure for 277 (55\%) sites, and hypermethylation for 223 (45\%) sites (all infants, test if more hypomethylation than expected gave $P=0.018)$. There were major sex differences: among boys 372 (74\%) of the top 500 sites showed hypomethylation with increasing arsenic exposure, compared with only 207 (41\%) among girls (difference between boys and girls $P$-value $<0.001$, Fisher's exact test). We found no single overlap between the top 500 arsenic-related sites in boys and those in girls. The $20 \mathrm{CpG}$ sites with the strongest association with urinary arsenic in GW 8 in boys and girls are listed in Table 2. Generally, stronger associations were found for boys compared with girls, as estimated from correlation coefficients and $P$-values; three $\mathrm{CpG}$ sites in boys (cg15255455, cg13659051 and cg17646418), but none in girls, were significantly associated with arsenic exposure after adjustment for multiple comparisons (Table 2). 
Table 1. Characteristics of the 127 mother-child pairs and all other women enrolled in the MINIMat trial ${ }^{a}$

\begin{tabular}{|c|c|c|}
\hline & Study sample $(n=127)$ & All women $(n=1729)$ \\
\hline Variables & Mean \pm S.D. or median (5-95 percentiles) or $n(\%)$ & Mean \pm S.D. or median (5-95 percentiles) or $n(\%)$ \\
\hline \multicolumn{3}{|l|}{ Maternal characteristics } \\
\hline Maternal age (years) & $25.3 \pm 5.9$ & $26.4 \pm 5.9$ \\
\hline BMI $\left(\mathrm{kg} / \mathrm{m}^{2}\right)$ at $\mathrm{GW} 8$ & $20.4 \pm 3.0$ & $20.1 \pm 2.7$ \\
\hline Parity (no. of children) & $1.1 \pm 1.4$ & $1.4 \pm 1.4$ \\
\hline $0 / \geqslant 1$ & $54(43 \%) / 73(57 \%)$ & $548(32 \%) / 1179(68 \%)$ \\
\hline Gestational age (week, GW) & $38.7 \pm 1.8$ & $38.8 \pm 2.1$ \\
\hline$<37 / \geqslant 37$ & $12(10 \%) / 112(90 \%)$ & $254(15 \%) / 1444(85 \%)$ \\
\hline \multicolumn{3}{|l|}{ Betel chewing during pregnancy } \\
\hline Yes/No & $73(58 \%) / 52(42 \%)$ & $1150(68 \%) / 531(32 \%)$ \\
\hline \multicolumn{3}{|l|}{ Socioeconomic status } \\
\hline Lowest & $19(15 \%)$ & $315(18 \%)$ \\
\hline Lower middle & $12(9 \%)$ & $349(20 \%)$ \\
\hline Middle & $24(19 \%)$ & $353(20 \%)$ \\
\hline Upper middle & $36(28 \%)$ & $350(20 \%)$ \\
\hline Highest & $36(28 \%)$ & $362(21 \%)$ \\
\hline Urinary arsenic GW $8(\mu \mathrm{g} / \mathrm{l})^{\mathrm{b}}$ & $66(20-457)$ & $66(17-466)^{\mathrm{c}}$ \\
\hline Inorganic arsenic $(\%)^{\mathrm{d}}$ & $13.8 \pm 5.5$ & na \\
\hline MMA $(\%)^{\mathrm{d}}$ & $10.06 \pm 3.6$ & na \\
\hline DMA $(\%)^{\mathrm{d}}$ & $76.12 \pm 7.5$ & na \\
\hline Urinary arsenic GW $30(\mu \mathrm{g} / \mathrm{l})^{\mathrm{d}}$ & $89(18-562)$ & $80(19-610)^{c}$ \\
\hline \multicolumn{3}{|l|}{ Infant characteristics } \\
\hline Birth weight $(\mathrm{g})$ & $2780 \pm 395$ & $2709 \pm 409$ \\
\hline Low birth weight $(<2500 \mathrm{~g})$ & $26(21 \%)$ & $504(25 \%)$ \\
\hline Sex (\% girls) & $65(51 \%)$ & $845(49 \%)$ \\
\hline
\end{tabular}

BMI, body mass index; GW, gestational week; MMA, methylarsonic acid; DMA, dimethylarsinic acid.

${ }^{\text {a } E n r o l l m e n t ~ i n ~ t h e ~ M I N I M a t ~ t r i a l ~ f r o m ~ O c t o b e r ~} 2002$ to October 2003.

${ }^{\mathrm{b}}$ Adjusted to average specific gravity of $1.012 \mathrm{~g} / \mathrm{ml}$.

${ }^{c}$ In MINIMat, urinary arsenic was measured at GW $8(n=1729)$ and GW $30(n=1031)$

${ }^{\mathrm{d}}$ Percent of total metabolite concentration in urine. Urinary arsenic refers to inorganic arsenic and its methylated metabolites in urine.

(a)

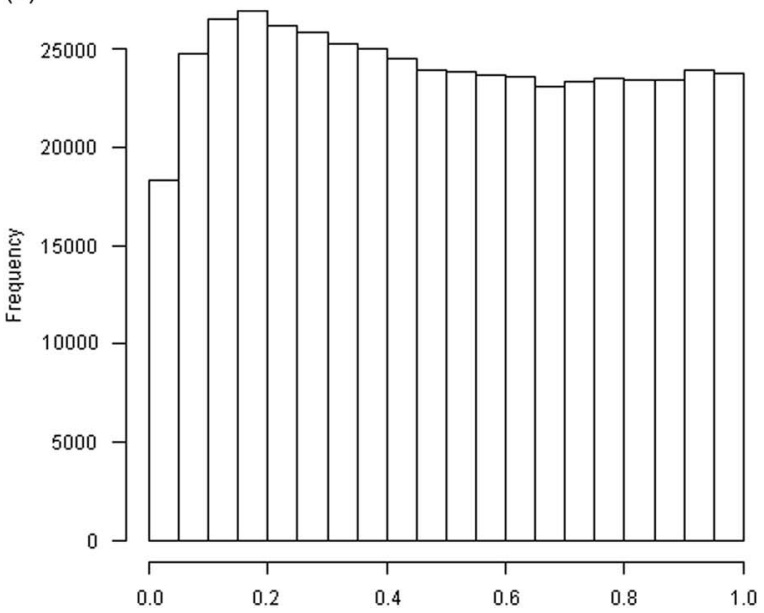

(b)

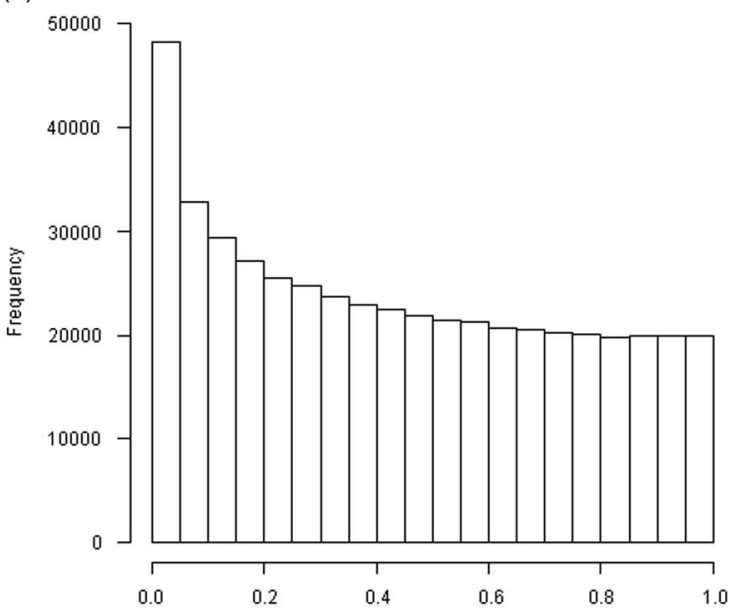

Fig. 1. Distribution of the $P$-values for the coefficient associated with maternal urinary arsenic concentrations in early gestation from linear regression analysis of CpG methylation ( $n=482,421$ sites) in cord blood. (a) Cord blood from girls, (b) Cord blood from boys. 
Table 2. Top 20 Cp G sites with the strongest correlations $\left(\mathrm{r}_{\mathrm{S}}\right)$ with maternal urinary arsenic concentrations in gestational week ( $\left.G W\right) 8$ by child sex, as well as regression analysis $(G W)^{a}$

\begin{tabular}{|c|c|c|c|c|c|c|c|c|c|c|}
\hline$\underline{\text { CpG sites }}$ & Chr & Gene & $r_{S}(\mathrm{GW} \mathrm{8)}$ & $P$-value & $\mathrm{FDR}^{\mathrm{b}}$ & $r_{s}(\mathrm{GW} 30)$ & $P$-value & $\mathrm{FDR}^{\mathrm{b}}$ & Regression $\beta$ GW $8(95 \% \mathrm{CI})^{\mathrm{c}}$ & $P$-value \\
\hline \multicolumn{11}{|l|}{ Boys } \\
\hline $\operatorname{cg} 15255455$ & 19 & PLIN5 & -0.62 & $1.3 \times 10^{-7}$ & 0.031 & -0.41 & $<0.001$ & 0.99 & $-0.016(-0.022,-0.0092)$ & $<0.001$ \\
\hline $\operatorname{cg} 13659051$ & 9 & LRRC26 & -0.62 & $1.3 \times 10^{-7}$ & 0.031 & -0.25 & 0.053 & 0.99 & $-0.018(-0.026,-0.0098)$ & $<0.001$ \\
\hline $\operatorname{cg} 17646418$ & 6 & RPS6KA2 & -0.61 & $2.3 \times 10^{-7}$ & 0.036 & -0.22 & 0.093 & 0.99 & $-0.011(-0.017,-0.0066)$ & $<0.001$ \\
\hline $\operatorname{cg} 02975107$ & 17 & & -0.58 & $1.1 \times 10^{-6}$ & 0.080 & -0.42 & $<0.001$ & 0.99 & $-0.0099(-0.014,-0.0050)$ & $<0.001$ \\
\hline $\operatorname{cg} 00592460$ & 6 & & -0.57 & $1.3 \times 10^{-6}$ & 0.080 & -0.29 & 0.022 & 0.99 & $-0.020(-0.027,-0.012)$ & $<0.001$ \\
\hline $\operatorname{cg} 05114100$ & $\mathrm{X}$ & LUZP4 & -0.57 & $1.4 \times 10^{-6}$ & 0.080 & -0.34 & 0.0073 & 0.99 & $-0.012(-0.018,-0.0059)$ & $<0.001$ \\
\hline cg23727087 & 12 & & -0.57 & $1.7 \times 10^{-6}$ & 0.080 & -0.15 & 0.24 & 0.99 & $-0.0089(-0.013,-0.0046)$ & $<0.001$ \\
\hline $\operatorname{cg} 17158414$ & 2 & KRTCAP3 & -0.57 & $1.7 \times 10^{-6}$ & 0.080 & -0.39 & 0.0018 & 0.99 & $-0.027(-0.041,-0.013)$ & $<0.001$ \\
\hline cg24042517 & 17 & HOXB9 & -0.57 & $1.7 \times 10^{-6}$ & 0.080 & -0.33 & 0.0084 & 0.99 & $-0.010(-0.01,-0.0055)$ & $<0.001$ \\
\hline cg12124733 & $\mathrm{X}$ & $D D X 26 B$ & 0.57 & $1.8 \times 10^{-6}$ & 0.080 & 0.30 & 0.018 & 0.99 & $0.0069(0.00086,0.013)$ & 0.026 \\
\hline $\operatorname{cg} 19802390$ & 1 & & -0.56 & $1.9 \times 10^{-6}$ & 0.080 & -0.18 & 0.16 & 0.99 & $-0.023(-0.034,-0.011)$ & $<0.001$ \\
\hline cg24456094 & 6 & $M D G A 1$ & -0.56 & $2.1 \times 10^{-6}$ & 0.080 & -0.30 & 0.015 & 0.99 & $-0.012(-0.018,-0.0054)$ & 0.001 \\
\hline $\operatorname{cg} 15479387$ & 6 & $H L A-F-A S 1$ & -0.56 & $2.2 \times 10^{-6}$ & 0.080 & -0.27 & 0.032 & 0.99 & $-0.0047(-0.0069,-0.0025)$ & $<0.001$ \\
\hline cg25938735 & 8 & & -0.56 & $2.5 \times 10^{-6}$ & 0.085 & -0.22 & 0.079 & 0.99 & $-0.014(-0.019,-0.0078)$ & $<0.001$ \\
\hline cg20415517 & 11 & BRSK2 & -0.55 & $2.8 \times 10^{-6}$ & 0.085 & -0.28 & 25 & 0.99 & $-0.013(-0.018,-0.0072)$ & $<0.001$ \\
\hline $\operatorname{cg} 12094808$ & 15 & FRMD5 & -0.55 & $2.8 \times 10^{-6}$ & 0.085 & -0.30 & 16 & 0.99 & $-0.011(-0.016,-0.0059)$ & $<0.001$ \\
\hline cg14920289 & 14 & SLC22A17 & -0.55 & $3.6 \times 10^{-6}$ & 0.095 & -0.36 & 0.0039 & 0.99 & $-0.0098(-0.014,-0.0052)$ & $<0.001$ \\
\hline cg21097283 & 5 & OTP & 0.55 & $3.9 \times 10^{-6}$ & 0.095 & 0.25 & 0.052 & 0.99 & $0.0093(0.0045,0.014)$ & $<0.001$ \\
\hline cg17322444 & 19 & GPATCH1 & 0.54 & $4.5 \times 10^{-6}$ & 0.095 & 0.25 & 0.045 & 0.99 & $0.0044(0.0026,0.0061)$ & $<0.001$ \\
\hline $\operatorname{cg} 24680320$ & 19 & & -0.54 & $4.5 \times 10^{-6}$ & 0.095 & -0.29 & 0.019 & 0.99 & $-0.0030(-0.0043,-0.0017)$ & $<0.001$ \\
\hline \multicolumn{11}{|l|}{ Girls } \\
\hline $\operatorname{cg} 22614624$ & 2 & $D T Y M K$ & 0.55 & $3.2 \times 10^{-6}$ & 0.52 & 0.24 & 3 & 0.99 & , 0.019) & 0.001 \\
\hline $\operatorname{cg} 08421080$ & 12 & RIMBP2 & 0.54 & $4.5 \times 10^{-6}$ & 0.52 & 0.39 & 0.0014 & 0.99 & $(0.0010,0.015)$ & 0.026 \\
\hline cg02240066 & 2 & & -0.54 & $5.0 \times 10^{-6}$ & 0.52 & -0.05 & 0.67 & 0.99 & $-0.0052(-0.0079,-0.0025)$ & $<0.001$ \\
\hline $\operatorname{cg} 09606015$ & 3 & $A T P 11 B$ & -0.54 & $5.3 \times 10^{-6}$ & 0.52 & -0.16 & 0.22 & 0.99 & $-0.0072(-0.011,-0.0032)$ & 0.001 \\
\hline $\operatorname{cg} 06411879$ & 10 & $N E B L$ & 0.54 & $5.4 \times 10^{-6}$ & 0.52 & 0.27 & 0.029 & 0.99 & $0.013(0.0040,0.021)$ & 0.005 \\
\hline $\operatorname{cg} 23385248$ & 15 & & -0.53 & $9.8 \times 10^{-6}$ & 0.61 & -0.31 & 0.012 & 0.99 & $-0.013(-0.020,-0.0063)$ & $<0.001$ \\
\hline $\operatorname{cg} 08962682$ & 12 & $R I M K L B$ & -0.52 & $1.5 \times 10^{-5}$ & 0.61 & -0.22 & 0.074 & 0.99 & $-0.0036(-0.0061,-0.0011)$ & 0.005 \\
\hline $\operatorname{cg} 05173913$ & 17 & C17orf50 & -0.50 & $3.0 \times 10^{-5}$ & 0.61 & -0.25 & 0.043 & 0.99 & $-0.0062(-0.010,-0.0017)$ & 0.007 \\
\hline cg21587006 & 10 & & 0.50 & $3.0 \times 10^{-5}$ & 0.61 & 0.34 & 0.0053 & 0.99 & $0.054(0.0024,0.10)$ & 0.040 \\
\hline $\operatorname{cg} 06584028$ & 2 & GFPT1 & -0.50 & $3.4 \times 10^{-5}$ & 0.61 & -0.20 & 0.12 & 0.99 & $-0.0053(-0.0080,-0.0027)$ & $<0.001$ \\
\hline $\operatorname{cg} 04361852$ & 11 & $U C P 2$ & -0.49 & $3.5 \times 10^{-5}$ & 0.60 & -0.14 & 0.27 & 0.99 & $-0.0043(-0.0072,-0.0013)$ & 0.005 \\
\hline $\operatorname{cg} 00384577$ & 19 & ITPKC & -0.48 & $4.9 \times 10^{-5}$ & 0.60 & -0.19 & 0.13 & 0.99 & $-0.0052(-0.0078,-0.0024)$ & $<0.001$ \\
\hline $\operatorname{cg} 14862981$ & 5 & & -0.48 & $5.3 \times 10^{-5}$ & 0.60 & -0.14 & 0.27 & 0.99 & $-0.0027(-0.0048,-0.00064)$ & 0.01 \\
\hline $\operatorname{cg} 09005548$ & 6 & ZBTB22 & 0.48 & $5.6 \times 10^{-5}$ & 0.60 & 0.23 & 0.061 & 0.99 & $0.011(0.0053,0.016)$ & $<0.001$ \\
\hline $\operatorname{cg} 14673387$ & 10 & & -0.48 & $5.8 \times 10^{-5}$ & 0.60 & -0.098 & 0.44 & 0.99 & $-0.0033(-0.0049,-0.0016)$ & $<0.001$ \\
\hline cg22328208 & 8 & TSPYL5 & -0.48 & $6.2 \times 10^{-5}$ & 0.60 & -0.29 & 0.017 & 0.99 & $-0.015(-0.025,-0.0043)$ & 0.007 \\
\hline $\operatorname{cg} 07276007$ & 11 & $A P 2 A 2$ & 0.48 & $6.8 \times 10^{-5}$ & 0.60 & 0.38 & 0.0017 & 0.99 & $0.0092(0.0012,0.017)$ & 0.024 \\
\hline $\operatorname{cg} 07936037$ & 6 & SSR1 & -0.48 & $6.9 \times 10^{-5}$ & 0.60 & -0.15 & 0.24 & 0.99 & $-0.0026(-0.0043,-0.00082)$ & 0.005 \\
\hline cg26726230 & 17 & SLC38A10 & 0.47 & $7.0 \times 10^{-5}$ & 0.60 & 0.038 & 0.76 & 0.99 & $0.024(0.011,0.036)$ & $<0.001$ \\
\hline $\operatorname{cg} 01094684$ & 19 & $U Q C R$ & -0.47 & $7.1 \times 10^{-5}$ & 0.60 & -0.28 & 0.021 & 0.99 & $-0.0033(-0.0053,-0.0012)$ & 0.002 \\
\hline
\end{tabular}

Chr, chromosome number; FDR, false discovery rate; CI, confidence intervals

In the regression analysis, the arsenic exposure variable was log2-transformed.

${ }^{\text {a C}}$ Correlations in GW 30 are also shown.

${ }^{\mathrm{b}} P$-value adjusted for FDR.

${ }^{\mathrm{c}}$ Adjusted for mother age, body mass index, gestational age at birth, socioeconomic status, exact gestational weeks at urine collection.

There were stronger associations between DNA methylation and maternal arsenic exposure measured in early than in late gestation, but the directions were the same. Examples of the associations are given in Fig. 2, which indicate that the effects of arsenic on DNA methylation start at low exposure levels, well below $100 \mu \mathrm{g} / \mathrm{l}$.

For the CpG sites in Table 2, only 1 (cg22614624) of the 40 sites contained an single-nucleotide polymorphism (SNP) 

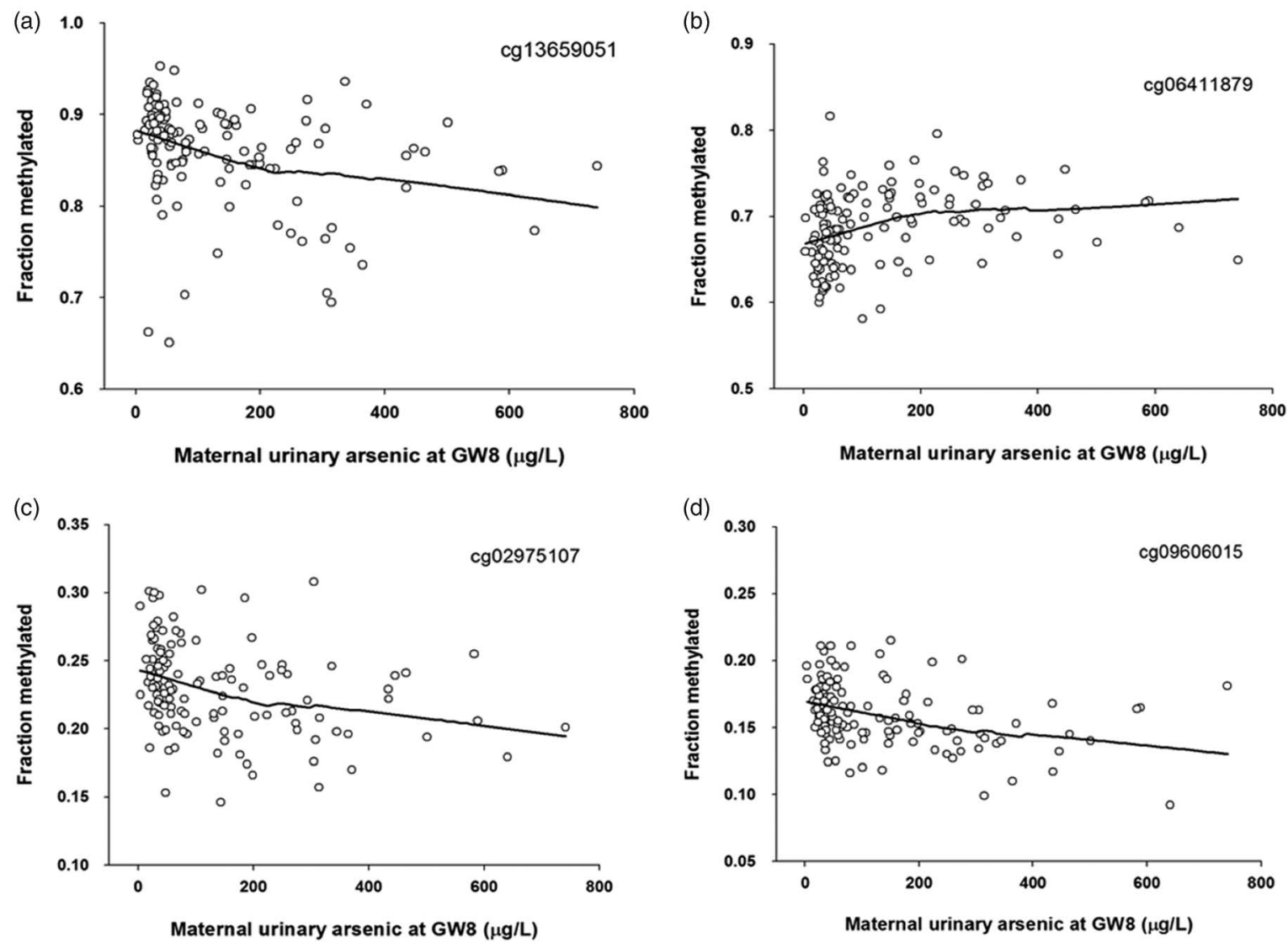

Figure 2. Scatterplot of the fractions ( 0 to 1 ) of methylation of the CpG sites in cord blood and the concentrations of arsenic metabolites in maternal urine in early pregnancy (gestational week 8) for: (a) cg13659051 and (c) cg02975107, among top five CpG sites in boys; and (b) $\operatorname{cg} 06411879$ and (d) cg09606015, among top five CpG sites in girls. The associations are indicated by Lowess lines.

within $\leqslant 10$ bp from the query site (Supplementary Table S2). This SNP has a minor allele frequency of 0.349 , based on very little data and none from Asian populations (www.ncbi.nlm. nih.gov/projects/SNP). We also analyzed the data without the sex chromosomes, but this did not influence the results. The reported $P$-values were still significant as well as the order of the top SNPs reported.

In the subsequent linear regression analyses ( $\log 2-$ transformed urinary arsenic concentrations in GW 8), the associations between $\mathrm{CpG}$ methylation and arsenic exposure in early gestation were very robust when taking other potentially influential covariates into account (Table 2). Apart from GW of urine collection, few covariates were even close to significant in the models and their inclusion did not markedly change the estimates for arsenic. In a sensitivity analysis, we additionally adjusted for birth weight, betel chewing and maternal cadmium in blood, but this only marginally changed the effect estimates. Among the 20 top sites in boys, the effect of arsenic on the degree of $\mathrm{CpG}$ methylation ranged between 0.3 and $2.7 \%$ for a doubling of arsenic concentrations in maternal urine $(\mu \mathrm{g} / \mathrm{l})$ in early pregnancy. Arsenic caused in boys mainly lower methylation (all 12 sites with $>1 \%$ change involved hypomethylation). The corresponding range for girls was $0.3-5.4 \%$ (of the seven sites with $>1 \%$ change, two showed lower and five higher methylation).

We performed analysis of LINE1 in a subgroup of 40 boys and 40 girls. There were no significant differences in LINE1 methylation (expressed as mean percentage of methylation of the four CpG sites) between the sexes (mean $68.0 \%$ in boys and $68.3 \%$ in girls, $P=0.75$, ANOVA). Furthermore, there were no significant associations between urinary arsenic in GW 8 and LINE1 methylation in all newborns $(P=0.86$, adjusted for the same covariates as in the analysis above for individual CpG sites $P=0.59$, ANCOVA), or in boys or girls separately (boys: $P=0.73$, adjusted $P=0.59$; girls: $P=0.46$, adjusted $P=0.45)$.

We additionally stratified the regression analyses by the percentage of MMA in urine (GW 8), as a measure of maternal arsenic methylation efficiency, mothers with relatively high percentage of MMA were considered to have poorer methylation efficiency (Supplementary Table S3). For several of the top 20 sites, the arsenic-related effect on CpG methylation was markedly stronger in newborns to mothers with poor arsenic methylation. 
Table 3. Pathway analysis ${ }^{a}$, stratified for sex, between maternal urinary arsenic concentrations in early gestation Cp $G$ methylation in cord blood

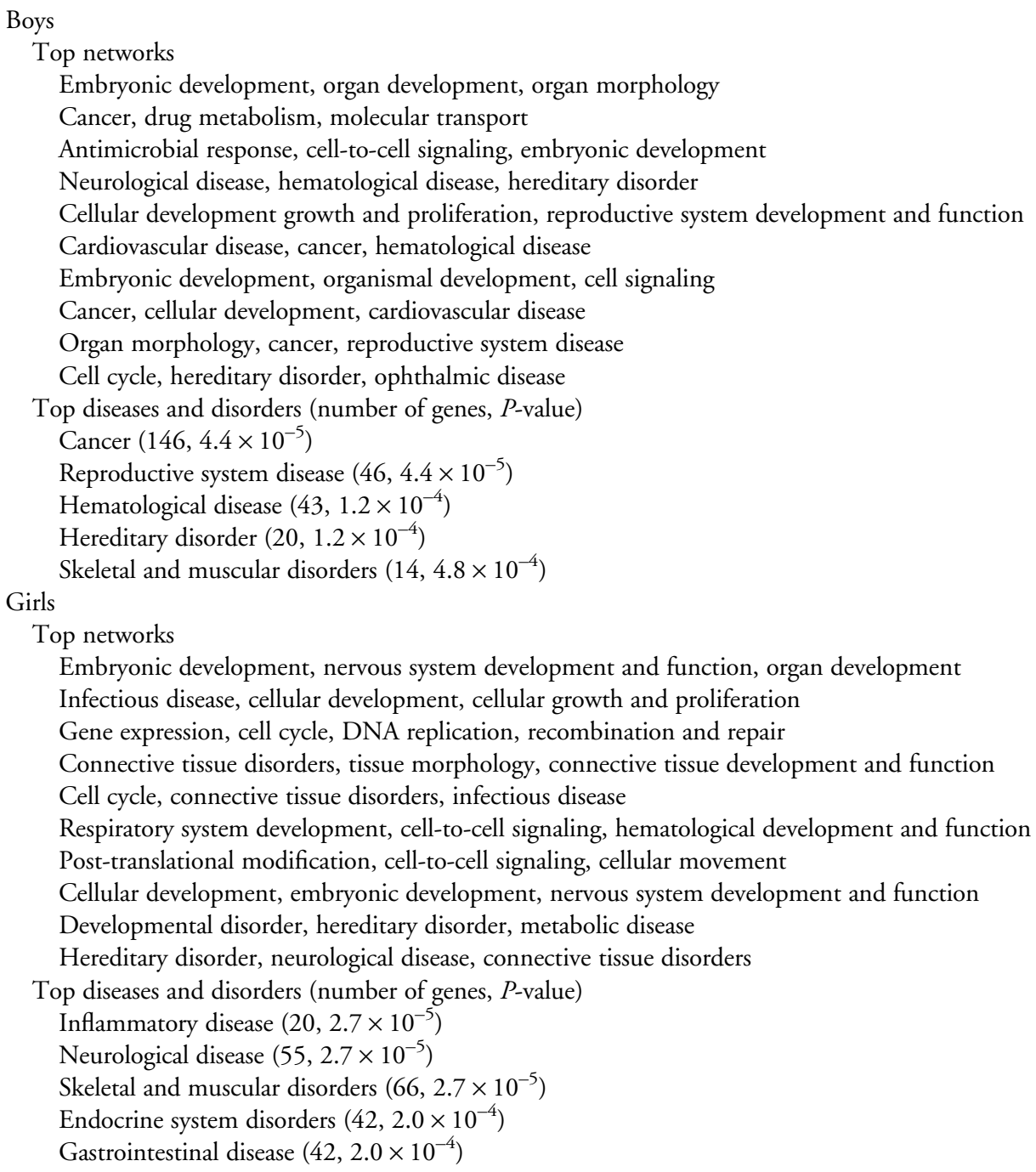

${ }^{\text {a }}$ The input data to the Ingenuity Pathway Analysis software was the top annotated genes from the top 500 scoring CpG sites in cord blood correlated to arsenic in maternal blood in boys and girls, respectively.

\section{Arsenic exposure in early gestation and epigenetic changes related to disease pathways}

We performed pathway analysis of the top 500 gene-annotated CpG sites for which methylation was affected by arsenic in boys and girls. In both boys and girls, there was overrepresentation of networks related to embryonic, organic and cellular development (Table 3). In contrast, cancer-related networks were found to be overrepresented in boys (146 genes, Supplementary Table S4), but not in girls. Of the 146 genes, $67 \%$ were hypomethylated with increasing arsenic exposure, the remaining were hypermethylated. When searching for related diseases that were overrepresented in boys, cancer was the first one listed $\left(P\right.$-value $\left.=4.4 \times 10^{-5}\right)$ followed by reproductive system diseases, hematological diseases, hereditary disorder, and skeletal and muscular disorders. In girls, inflammatory disease ranked the highest $\left(P\right.$-value $\left.=2.7 \times 10^{-5}\right)$, followed by neurological diseases, skeletal and muscular disorders, endocrine system disorders and gastrointestinal diseases.

We performed linear regression analysis of the top $10 \mathrm{CpG}$ sites identified among the 146 genes associated with cancer in boys (and in girls for comparison). The results (Table 4) show that the associations in boys were robust in the models, and that methylation in these sites was not associated with arsenic in girls. Three CpG sites (cg13659051, cg24042517 and cg20415517) associated with cancer-related genes were also among the top sites in Table 2: LRRC26, HOXB9 and BRSK2. 
Table 4. Top 10 cancer-related $C p G$ sites in boys (and girls for comparison) with the strongest correlations ( $\mathrm{r}_{\mathrm{S}}$ ) with maternal arsenic urinary concentrations in gestational week 8

\begin{tabular}{|c|c|c|c|c|c|c|c|}
\hline CpG sites & Chr & Gene & $r_{S}$ & $P$-value & $\mathrm{FDR}^{\mathrm{a}}$ & $\beta(95 \% \mathrm{CI})^{\mathrm{b}}$ & $P$-value \\
\hline \multicolumn{8}{|l|}{ Boys } \\
\hline $\operatorname{cg} 13659051$ & 9 & $L R R C 26$ & -0.62 & $1.3 \times 10^{-7}$ & 0.031 & $-0.018(-0.026,-0.0098)$ & $<0.001$ \\
\hline cg24042517 & 17 & HOXB9 & -0.57 & $1.7 \times 10^{-6}$ & 0.080 & $-0.010(-0.015,-0.0055)$ & $<0.001$ \\
\hline cg20415517 & 11 & $B R S K 2$ & -0.56 & $2.8 \times 10^{-6}$ & 0.085 & $-0.013(-0.018,-0.0072)$ & $<0.001$ \\
\hline $\operatorname{cg} 04517524$ & 14 & $A S B 2$ & -0.55 & $5.2 \times 10^{-6}$ & 0.095 & $-0.022(-0.032,-0.011)$ & $<0.001$ \\
\hline $\operatorname{cg} 26243679$ & 6 & FRK & -0.52 & $1.2 \times 10^{-5}$ & 0.10 & $-0.014(-0.021,-0.0069)$ & $<0.001$ \\
\hline $\operatorname{cg} 08660959$ & 6 & $T N X B$ & -0.52 & $1.2 \times 10^{-5}$ & 0.10 & $-0.0046(-0.0069,-0.0021)$ & $<0.001$ \\
\hline $\operatorname{cg} 06611850$ & 3 & DPPA2 & -0.52 & $1.3 \times 10^{-5}$ & 0.10 & $-0.014(-0.021,-0.0066)$ & $<0.001$ \\
\hline $\operatorname{cg} 21050076$ & 19 & $G C D H$ & -0.52 & $1.3 \times 10^{-5}$ & 0.10 & $-0.0092(-0.013,-0.0048)$ & $<0.001$ \\
\hline cg21856067 & 20 & MACROD2 & -0.52 & $1.3 \times 10^{-5}$ & 0.10 & $-0.0053(-0.0081,-0.0025)$ & $<0.001$ \\
\hline $\operatorname{cg} 24698211$ & 5 & $F G F 18$ & -0.52 & $1.5 \times 10^{-5}$ & 0.10 & $-0.016(-0.024,-0.0069)$ & $<0.001$ \\
\hline \multicolumn{8}{|l|}{ Girls } \\
\hline $\operatorname{cg} 13659051$ & 9 & LRRC26 & -0.20 & 0.10 & 0.61 & $-0.00092(-0.012,0.011)$ & 0.88 \\
\hline cg24042517 & 17 & HOXB9 & -0.14 & 0.26 & 0.68 & $-0.0019(-0.0086,0.0049)$ & 0.58 \\
\hline cg20415517 & 11 & BRSK2 & 0.10 & 0.41 & 0.75 & $0.0037(-0.0051,0.012)$ & 0.41 \\
\hline $\operatorname{cg} 04517524$ & 14 & $A S B 2$ & 0.17 & 0.16 & 0.63 & $-0.00038(-0.017,0.016)$ & 0.96 \\
\hline $\operatorname{cg} 26243679$ & 6 & FRK & 0.0065 & 0.95 & 0.98 & $0.0038(-0.0043,0.011)$ & 0.36 \\
\hline $\operatorname{cg} 08660959$ & 6 & $T N X B$ & -0.07 & 0.54 & 0.83 & $0.00013(-0.0035,0.0038)$ & 0.94 \\
\hline $\operatorname{cg} 06611850$ & 3 & DPPA2 & -0.15 & 0.25 & 0.67 & $0.00028(-0.0089,0.0094)$ & 0.95 \\
\hline cg21050076 & 19 & $G C D H$ & -0.06 & 0.63 & 0.86 & $-0.0029(-0.0085,0.0028)$ & 0.32 \\
\hline cg21856067 & 20 & MACROD2 & -0.22 & 0.85 & 0.95 & $-0.0018(-0.0066,0.0029)$ & 0.44 \\
\hline $\operatorname{cg} 24698211$ & 5 & $F G F 18$ & -0.18 & 0.13 & 0.62 & $-0.0018(-0.012,0.0089)$ & 0.74 \\
\hline
\end{tabular}

Chr, chromosome number; FDR, false discovery rate; CI, confidence intervals.

In the regression analysis arsenic exposure variable was $\log 2$-transformed.

${ }^{\text {a }} P$-value adjusted for FDR.

${ }^{\mathrm{b}}$ Adjusted for mother's age, body mass index, gestational age at birth, socioeconomic status, exact gestational weeks at urine collection.

\section{Discussion}

This first study of sex-differential genome-wide cord blood DNA methylation in relation to arsenic exposure provides strong evidence that maternal arsenic exposure in early gestation is associated with modified DNA methylation in the newborn child. For many of the $\mathrm{CpG}$ sites, arsenic exposure changed the DNA methylation by several percent, and the changes started at low exposure levels, below $50 \mu \mathrm{g} / \mathrm{l}$ in the urine. At the genome-wide DNA methylation level, the associations with arsenic exposure were much more evident in boys than in girls. In particular, arsenic seemed to induce hypomethylation in boys; that is, in 74 of the top $500 \mathrm{CpG}$ sites methylation decreased with increasing arsenic exposure. In a subgroup of the newborns, we evaluated whether the decrease in methylation with increasing arsenic exposure in boys, reflects a general genomic feature, such as interference of arsenic with the methyl donor pool. However, we did not find any overall effect of arsenic on global methylation in either of the sexes. Furthermore, we did not observe multiple probes affected for individual genes but rather strong effects on individual $\mathrm{CpG}$ sites in relation to arsenic. This observation, together with the data for global methylation, suggests that arsenic affects accessible areas of the chromatin with, certain structural features, or impacts on specific transcription factors or other chromatin-associated proteins. The pathway analysis showed enrichment of DNA methylation changes in cancer-related genes in boys, but not in girls. This is interesting considering the reported sex differences in cancer development in mice following prenatal arsenic exposure, with later-life occurrence of liver carcinoma and adrenal cortical adenoma in male, but not female, offspring. ${ }^{44}$ A further observation is noteworthy in relation to our data that the follow-up of the male liver DNA showed significant reduction in methylation of GC-rich regions. ${ }^{19}$ In contrast, mice that were continuously exposed also after birth showed much less sex differences in cancer development, ${ }^{45}$ which is in agreement with the observed marked increase in liver cancer mortality in both boys and girls exposed to arsenic through drinking water in northern Chile as young children, but not in those exposed before birth. ${ }^{15}$ It should be noted that we have identified arsenic-related impaired fetal growth in boys, ${ }^{46}$ although postnatal growth seems to be more affected in girls. ${ }^{14}$ Here we identified different processes involved in development, as the top pathways for arsenic-related DNA methylation change in both boys and girls. One can speculate that arsenic might interfere with 
already existing sex-specific gene expression early in life ${ }^{31}$ as seen in mice exposed to arsenic, ${ }^{47}$ or alternatively it causes sex-specific DNA methylation for genes that should not differ between the sexes. Thus, it is essential to follow-up on the epigenetic effects of arsenic as the children grow.

The much stronger associations with arsenic exposure in early compared with late gestation may reflect interference with the de novo DNA methylation patterns established in early fetal development. ${ }^{5}$ The rapid upregulation of the second step in arsenic methylation, resulting in a decrease in the percentage of the most toxic metabolite MMA very early in pregnancy, ${ }^{38}$ may further contribute to the observed weaker epigenetic associations with late gestation exposure levels. Indeed, our data also suggest that a low capacity for methylation of arsenic, resulting in a higher fraction of urinary MMA, a known susceptibility factor for arsenic toxicity, ${ }^{40,41}$ was associated with stronger epigenetic effects. However, the results in relation to methylation capacity need to be followed up, as they were based on a small number of children in each comparison group. Koestler et $a{ }^{30}{ }^{30}$ also found the effects of prenatal exposure to arsenic on cord blood methylation; however, in contrast to our data, they found increasing methylation with increasing arsenic exposure for most top sites. The results are difficult to compare with ours as the women in their study had markedly lower exposure (median maternal urinary arsenic was $4 v .66 \mu \mathrm{g} / \mathrm{l}$ in our study) measured late in pregnancy, and moreover they did not stratify their results for sex.

The top sites associated with arsenic might represent possible new candidates for arsenic epigenome toxicity. In boys, three CpG sites associated with different genes (PLIN5, LRRC26 and $R P S 6 K A)$, not previously linked to arsenic, were significantly hypomethylated in relation to arsenic exposure. Perilipin 5 (PLIN5) is a lipid metabolism-related protein; overexpression of PLIN5 in rat skeletal muscle promoted oxidative gene expression and intramyocellular lipid content. ${ }^{48}$ Heart-specific overexpression of PLIN5 in mice was associated with increased triglyceride concentrations and strong increased expression of oxidative-induced genes via NF-E2-related factor 2 antioxidative pathway. ${ }^{49}$ LRRC26 is a protein associated with calcium-activated potassium channels, so-called BK channels. It is normally expressed not only in the fetal brain and thymus, but also in prostate cancer where its expression actually reduced tumor growth and metastasis. ${ }^{50}$ RPS6KA is a type of serine/ threonine kinase, implicated in controlling cell growth and differentiation and it has been identified as a risk marker for colon and rectal cancer. ${ }^{51}$ In addition, $H O X B 9$ and BRKS 2 are worth mentioning as they were among the cancer-related genes and among the top 20 genes for boys. HOXB9, a class I homebox gene, is overexpressed in breast cancer and it induces an epithelial-to-mesenchymal transition, a key factor in metastasis. ${ }^{52}$ BRSK2 is an AMP-activated protein kinase and a multifunctional regulator of cell-cycle progression. Further studies are needed to examine the DNA methylation of these newly identified genes related to arsenic exposure later in life and in relation to cancer risk. Moreover, as we measure changes in DNA methylation in blood, they need to be followed up in relation to potential hematopoetic effects.

We have previously reported effects of maternal cadmium exposure on 5-methylcytosine methylation in the same cohort of newborns. ${ }^{7}$ However, the cadmium-associated sites were not overlapping with those identified here and adjustment for cadmium did not influence the result. Betel chewing was not influential in this study on arsenic, which might be owing to the fact that very few of the mothers mixed betel leaves with tobacco. Further adjustments for SES or other potential influential factors did not alter the associations; however, we cannot completely exclude that there might be residual confounding. A potential caveat of this study is that we were not able to sort cells in the blood samples during the field studies. We therefore measured DNA methylation in cord blood mononuclear cells, which are a mixture of different cell types with partly different methylation patterns. Thus, we cannot exclude that a potential cell-specific effect of arsenic might blur associations between DNA methylation and arsenic exposure. However, in the recent study by Koestler et al., ${ }^{30}$ white blood cell distributions explained only a small proportion of the variability in patterns of cord blood DNA methylation associated with maternal arsenic exposure (3\% for total arsenic in urine). Furthermore, some results from the Ingenuity Pathway Analysis (IPA) analysis, although plausible, should be carefully interpreted as a recent paper describes that certain diseases and pathways, for example, cancer and developmental-related pathways, tend to be overrepresented in the IPA. ${ }^{53}$

In conclusion, we show a clear relationship between maternal exposure to arsenic, especially in early pregnancy, and epigenetic effects early in life, particularly in boys. How that relates to the observed health effects of arsenic in early and later life remains to be elucidated. Our results emphasize the need to evaluate epigenetic effects of fetal environmental factors by sex and critical windows of exposure.

\section{Acknowledgments}

None.

\section{Financial Support}

This research was supported by the Swedish Council for Working Life and Social Research (K.B., co-PI), the Swedish Research Council (M.V., PI), the Swedish International Development Cooperation Agency (SIDA; M.V., PI) and the Karolinska Institutet (M.V.).

\section{Conflicts of Interest}

None.

\section{Ethical Standards}

The authors assert that all procedures contributing to this work comply with the ethical standards of the Helsinki Declaration 
of 1975 , as revised in 2008, and has been approved by the institutional committees Research Review Committee and Ethical Review Committee of ICDDR,B in Bangladesh and the Regional Ethics Committee at the Karolinska Institutet in Sweden.

\section{Supplementary material}

To view supplementary material for this article, please visit http://dx.doi.org/10.1017/S2040174414000221.

\section{References}

1. Gluckman PD. Epigenetics and metabolism in 2011: epigenetics, the life-course and metabolic disease. Nat Rev Endocrinol. 2011; 8, 74-76.

2. Attig L, Gabory A, Junien C. Early nutrition and epigenetic programming: chasing shadows. Curr Opin Clin Nutr Metab Care. 2010; 13, 284-293.

3. Barker DJ. Fetal growth and adult disease. Br J Obstet Gynaecol. 1992; 99, 275-276.

4. Bergman Y, Cedar H. DNA methylation dynamics in health and disease. Nat Struct Mol Biol. 2013; 20, 274-281.

5. Waterland RA, Michels KB. Epigenetic epidemiology of the developmental origins hypothesis. Annu Rev Nutr. 2007; 27, 363-388.

6. Baccarelli A, Bollati V. Epigenetics and environmental chemicals. Curr Opin Pediatr. 2009; 21, 243-251.

7. Kippler M, Engström K, Mlakar SJ, et al. Sex-specific effects of early life cadmium exposure on DNA methylation and implications for birth weight. Epigenetics. 2013; 8, 494-503.

8. Perera F, Herbstman J. Prenatal environmental exposures, epigenetics, and disease. Reprod Toxicol. 2011; 31, 363-373.

9. EFSA. Scientific opinion of the panel on contaminants in the food chain on a request from the European Commission on cadmium in food. EFSA J. 2009; 980, 1-139.

10. IARC. A Review of Human Carcinogens: Arsenic, Metals, Fibres, and Dusts. IARC Monographs on the Evaluation of Carcinogenic Risks to Humans. 2012. International Agency for Research on Cancer: Lyon.

11. Hamadani JD, Tofail F, Nermell B, et al. Critical windows of exposure for arsenic-associated impairment of cognitive function in pre-school girls and boys: a population-based cohort study. Int J Epidemiol. 2011; 40, 1593-1604.

12. Rahman A, Persson LA, Nermell B, et al. Arsenic exposure and risk of spontaneous abortion, stillbirth, and infant mortality. Epidemiology. 2010; 21, 797-804.

13. Rahman A, Vahter M, Ekstrom EC, Persson LA. Arsenic exposure in pregnancy increases the risk of lower respiratory tract infection and diarrhea during infancy in Bangladesh. Environ Health Perspect. 2011; 119, 719-724.

14. Saha KK, Engstrom A, Hamadani JD, et al. Pre- and postnatal arsenic exposure and body size to two years of age: a cohort study in rural Bangladesh. Environ Health Perspect. 2012; 120, 1208-1214.

15. Liaw J, Marshall G, Yuan Y, et al. Increased childhood liver cancer mortality and arsenic in drinking water in northern Chile. Cancer Epidemiol Biomarkers Prev. 2008; 17, 1982-1987.
16. Smith AH, Marshall G, Yuan Y, et al. Increased mortality from lung cancer and bronchiectasis in young adults after exposure to arsenic in utero and in early childhood. Environ Health Perspect. 2006; 114, 1293-1296.

17. Smith AH, Marshall G, Liaw J, et al. Mortality in young adults following in utero and childhood exposure to arsenic in drinking water. Environ Health Perspect. 2012; 120, 1527-1531.

18. Tokar EJ, Diwan BA, Waalkes MP. Arsenic exposure in utero and nonepidermal proliferative response in adulthood in Tg.AC mice. Int J Toxicol. 2010; 29, 291-296.

19. Xie Y, Liu J, Benbrahim-Tallaa L, et al. Aberrant DNA methylation and gene expression in livers of newborn mice transplacentally exposed to a hepatocarcinogenic dose of inorganic arsenic. Toxicology. 2007; 236, 7-15.

20. Yorifuji T, Tsuda T, Grandjean P. Unusual cancer excess after neonatal arsenic exposure from contaminated milk powder. $J$ Natl Cancer Inst. 2010; 102, 360-361.

21. Bhattacharjee P, Banerjee M, Giri AK. Role of genomic instability in arsenic-induced carcinogenicity. A review. Environ Int. 2013; 53, 29-40.

22. Du J, Zhou N, Liu H, et al. Arsenic induces functional re-expression of estrogen receptor alpha by demethylation of DNA in estrogen receptor-negative human breast cancer. PLoS One. 2012; 7, e35957.

23. Hansen KD, Timp W, Bravo HC, et al. Increased methylation variation in epigenetic domains across cancer types. Nat Genet. 2011; 43, 768-775.

24. Hossain MB, Vahter M, Concha G, Broberg K. Environmental arsenic exposure and DNA methylation of the tumor suppressor gene p16 and the DNA repair gene MLH1: effect of arsenic metabolism and genotype. Metallomics. 2012; 4, 1167-1175.

25. Jones PA, Baylin SB. The fundamental role of epigenetic events in cancer. Nat Rev Genet. 2002; 3, 415-428.

26. Smeester L, Rager JE, Bailey KA, et al. Epigenetic changes in individuals with arsenicosis. Chem Res Toxicol. 2011; 24, 165-167.

27. Intarasunanont $P$, Navasumrit $P$, Waraprasit $S$, et al. Effects of arsenic exposure on DNA methylation in cord blood samples from newborn babies and in a human lymphoblast cell line. Environ Health. 2012; 11, 31.

28. Kile ML, Baccarelli A, Hoffman E, et al. Prenatal arsenic exposure and DNA methylation in maternal and umbilical cord blood leukocytes. Environ Health Perspect. 2012; 120, 1061-1066.

29. Pilsner JR, Hall MN, Liu X, et al. Influence of prenatal arsenic exposure and newborn sex on global methylation of cord blood DNA. PLoS One. 2012; 7, e37147.

30. Koestler DC, Avissar-Whiting M, Houseman EA, Karagas MR, Marsit CJ. Differential DNA methylation in umbilical cord blood of infants exposed to low levels of arsenic in utero. Environ Health Perspect. 2013; 121, 971-977.

31. Gabory A, Attig L, Junien C. Developmental programming and epigenetics. Am J Clin Nutr. 2011; 94, 1943S-1952S.

32. Nohara K, Baba T, Murai H, et al. Global DNA methylation in the mouse liver is affected by methyl deficiency and arsenic in a sex-dependent manner. Arch Toxicol. 2011; 85, 653-661.

33. Rahman M, Vahter M, Wahed MA, et al. Prevalence of arsenic exposure and skin lesions. A population based survey in Matlab, Bangladesh. J Epidemiol Community Health. 2006; 60, 242-248. 
34. Winston JJ, Escamilla V, Perez-Heydrich C, et al. Protective benefits of deep tube wells against childhood diarrhea in Matlab, Bangladesh. Am J Public Health. 2013; 103, 1287-1291.

35. Persson LA, Arifeen S, Ekström EC, et al. Effects of prenatal micronutrient and early food supplementation on maternal hemoglobin, birth weight, and infant mortality among children in Bangladesh: the MINIMat randomized trial. JAMA. 2012; 307, 2050-2059.

36. Saha KK, Frongillo EA, Alam DS, et al. Household food security is associated with infant feeding practices in rural Bangladesh. J Nutr. 2008; 138, 1383-1390.

37. Vahter M, Li L, Nermell B, et al. Arsenic exposure in pregnancya population based study in Matlab, Bangladesh.J Health Popul Nutr. 2006; 24, 236-245.

38. Gardner RM, Nermell B, Kippler M, et al. Arsenic methylation efficiency increases during the first trimester of pregnancy independent of folate status. Reprod Toxicol. 2011; 31, 210-218.

39. Vahter M. Effects of arsenic on maternal and fetal health. Annu Rev Nutr. 2009; 29, 381-399.

40. Li H, Engström K, Vahter M, et al. Arsenic exposure through drinking water is associated with longer telomeres in peripheral blood. Chem Res Toxicol. 2012; 25, 2333-2339.

41. Pierce BL, Kibriya MG, Tong L, et al. Genome-wide association study identifies chromosome 10q24.32 variants associated with arsenic metabolism and toxicity phenotypes in Bangladesh. PLoS Genet. 2012; 8, e1002522.

42. Engström KS, Hossain MB, Lauss M, et al. Efficient arsenic metabolism - the AS3MT haplotype is associated with DNA methylation and expression of multiple genes around AS3MT. PLoS One. 2013; 8, e53732.

43. Hossain MB, Vahter M, Concha G, Broberg K. Low-level environmental cadmium exposure is associated with DNA hypomethylation in Argentinean women. Environ Health Perspect. 2012; 120, 879-884.
44. Waalkes MP, Liu J, Diwan BA. Transplacental arsenic carcinogenesis in mice. Toxicol Appl Pharmacol. 2007; 222, 271-280.

45. Tokar EJ, Diwan BA, Ward JM, Delker DA, Waalkes MP. Carcinogenic effects of 'whole-life' exposure to inorganic arsenic in CD1 mice. Toxicol Sci. 2011; 119, 73-83.

46. Kippler M, Wagatsuma Y, Rahman A, et al. Environmental exposure to arsenic and cadmium during pregnancy and fetal size: a longitudinal study in rural Bangladesh. Reprod Toxicol. 2012; 34, 504-511.

47. Waalkes MP, Liu J, Chen $\mathrm{H}$, et al. Estrogen signaling in livers of male mice with hepatocellular carcinoma induced by exposure to arsenic in utero. J Natl Cancer Inst. 2004; 96, 466-474.

48. Bosma M, Sparks LM, Hooiveld GJ, et al. Overexpression of PLIN5 in skeletal muscle promotes oxidative gene expression and intramyocellular lipid content without compromising insulin sensitivity. Biochim Biophys Acta. 2013; 1831, 844-852.

49. Wang H, Sreenivasan U, Gong DW, et al. Cardiomyocytespecific perilipin 5 overexpression leads to myocardial steatosis and modest cardiac dysfunction. J Lipid Res. 2013; 54, 953-965.

50. Liu XF, Xiang L, Zhang Y, et al. CAPC negatively regulates NF$\mathrm{\kappa B}$ activation and suppresses tumor growth and metastasis. Oncogene. 2012; 31, 1673-1682.

51. Slattery ML, Lundgreen A, Herrick JS, Wolff RK. Genetic variation in RPS6KA1, RPS6KA2, RPS6KB1, RPS6KB2, and PDK1 and risk of colon or rectal cancer. Mutat Res. 2011; 706, $13-20$.

52. Chiba N, Comaills V, Shiotani B, et al. Homeobox B9 induces epithelial-to-mesenchymal transition-associated radioresistance by accelerating DNA damage responses. Proc Natl Acad Sci. 2012; 109, 2760-2765.

53. Harper KN, Peters BA, Gamble MV. Batch effects and pathway analysis: two potential perils in cancer studies involving DNA methylation array analysis. Cancer Epidemiol Biomarkers Prev. 2013; 22, 1052-1060. 